\title{
10. Biohacking: Playing with technology
}

\author{
Stephanie de Smale
}

\begin{abstract}
This chapter examines the process of image production by open-source microscopes from the perspective of play. The question what happens to images when microscopes move from the lab to open-source hacker spaces is probed by deconstructing the material layers of its production. Politically motivated to democratize science, open-source translations transform the use and function of biotechnology. And while the process of translation may compromise microscopes' scientific capability, they gain in value from experimentation by artists and citizens. As a result, playing with biotechnology is an educative and creative exploration of the use and construction of scientific instruments, where the multi-layered process of making an image becomes observable to the naked eye.
\end{abstract}

Keywords: Hacking, biotechnology, citizen science, open source, materiality, objectivity

On 8 October 2013, a group of artists, activists, and scientists gathered at the Waag Society in Amsterdam to discuss the relationship between biotechnology, the life sciences, art, and hacking (G-netwerk 2013). A central topic of this evening was biohacking, an emerging term that is used to describe activities that aid in the democratization of science, such as hacking laboratory equipment to create open source equivalents. Biohacking tries to take science out of the lab (Delfanti 2012, 163). It is practiced in garages, open hacker spaces, or 'open wet labs,' and is facilitated through the production of low cost laboratory equipment based on open source hardware (OSHW). From a biohacker's perspective, these technologies emancipate science by enabling the production of data and knowledge by non-professionals in the public realm (Delfanti 2012; Kera and Dusseiller 2012). A prominent example of this is the open source do-it-yourself (DIY) microscope developed by

Glas, R., S. Lammes, M. de Lange, J. Raessens, and I. de Vries, eds. 2019. The Playful Citizen. Civic Engagement in a Mediatized Culture. Amsterdam: Amsterdam University Press. DOI: $10.5117 / 9789462984523 / \mathrm{CH} 10$ 
platform Hackteria.org. Users are free to create and adapt the design of these microscopes, and to produce data by creating images in any way they see fit. The appropriation of the microscope and the claim that biohacking is a counter-practice in the production of knowledge, makes it necessary to take a closer look at the production process of scientific images. Many scholars have written extensively about the role of microscopic images in scientific research (Knorr-Cetina and Amann 1990; Wise 2006; Daston and Galison 2007). Underlying their work is an oscillation between objectivity and subjectivity in scientific knowledge production, which has changed with the introduction of digital technology in (microscopic) image production. Digital scientific images are interactive and can be used, cropped, cut, and colored. The image is not fixed, but a result of the complex interrelation between producer, technology, and context.

Science historians Lorraine Daston and Peter Galison $(2007,382)$ recognize the introduction of digital image production as a shift from representation to presentation, "[i]mages in which the making is the seeing." Historian Norton Wise expresses a similar idea that visualization in science is not an illustration, but an argument $(2006,81)$. The microscope has been around for a while, but what does the appropriation of this device in different contexts, such as an open wetlab, do to scientific image production? Changing environments and settings can leave room for other, more playful encounters with (bio)technologies. This is also strongly associated with practices in citizen science projects that stimulate citizens to collect large amounts data for research projects. One example is the game Binary Fission (Verigames 2015), a puzzle game where users aid in testing the validity of algorithms. Using a microscopic perspective as a scientific backdrop for the game, the player works toward the formation of parts by moving them around. Both projects aim to involve citizens in knowledge production, but how do citizen science and biohacking relate to each other? Zooming in at biohacking in particular raises interesting questions about the cultural value vis-à-vis the scientific value of hacked lab equipment.

This chapter examines the process of image production in the DIY microscope from the perspective of play. Play is not tied to a particular activity, such as a game, but is brought out by a complex interrelation between people and their interactions with an object. It is an expression of creativity, which can be rebellious, political, and often goes against the grain. Indeed, as some scholars argue, play appropriates, distorts, and performs (Sicart 2014). Through the lens of play, I address the question of what happens to the production and appropriation of images when microscopes move from the lab to open source hacker spaces. The playful production and 
appropriation of Hackteria's DIY microscope serves as my main case study. Framing digitally distributed scientific images as objects in their own right brings attention to how they are made. Central to this argument is the text Objectivity (2007) by Daston and Galison, where scientific images are presented as tools that are interrelated with the producer and practice. Digital art and software scholar Ann-Sophie Lehmann asserts something similar by arguing that shaping the digital image is a craft with multiple layers of materiality $(2012,169)$. By materiality, I refer to both the physical materials, and social processes that shape the image. Using a similar approach as Lehmann, I conduct a material object analysis to uncover the material layers in the production of a DIY microscope. These layers constitute the process of encoding and decoding the microscope, such as the creation of prototypes, or digital schemata. Studying the translation of the microscope into the DIY microscope, I focus on the relationship between hacking as a playful practice and a process of creating knowledge.

First, by placing microscopic image production in the context of digital manipulation, I will analyze the relationship between microscopic image production and the notion of objectivity. Although this concept is highly contestable, it remains one of the pillars of modern science. Furthermore, by addressing how the producer, image, and practice are interrelated, I argue that this also creates space for a diversion of scientific practices. In the second section, I examine biohacking and the production of DIY microscopes to address the type of knowledge production afforded through the process of hacking and making. A citizen science game and biohacking are two different playful appropriations of science. The former is a game where the player collects data for the game's producers, the latter is an example of knowledge production through play as an iterative explorative process. Analyzing the production of the DIY microscope highlights how it is framed as an epistemic tool, where every translation or layer of materiality affects its message. In turn, the playful appropriation of the microscope shifts its epistemic message. Indeed, as the production process becomes an important part of the DIY microscope, the images tend to gain in cultural and educational value what they might lose in scientific appropriation. Furthermore, the context of play affords a specific form of knowledge production. This allows me to illustrate how play is firmly connected to hacker practices, and that biohacking is a critical product of playful experiments to liberate science. 


\section{Bringing science out of the lab}

Dividing this section into three parts, I focus first on the function of scientific images and microscopic image production in providing objective knowledge. This allows me to highlight the paradox of modern microscopic image production as both a symbolic function of objectivity, and a tool for digital manipulation in the second part. The ability to capture and manipulate images digitally invites scientists to play around with the aesthetics of their images, extending the function of these images to the cultural realm. As I will discuss in the third part, this extension also works the other way around, as citizen science games contribute to knowledge production through play.

\section{Function and manipulation of scientific images}

How does contemporary image practice affect the notion of objectivity in science? This question draws attention toward the function of image production in scientific research. Throughout scientific history, instruments have been considered an objective tool in visualizing nature. The invention of the microscope not only opened up a whole world of biology once hidden from the eye, but was used as a tool to observe nature on a micro scale through an objective lens. Its function is both constitutive and symbolic, as instruments like microscopy served as "a means to and a symbol of mechanical objectivity" (Daston and Galison 2007, 139). With the microscope as an objective mediator, scientists tried to eliminate the subject. The epistemic message of the microscope is a tool for creating objective knowledge. Today, more involvement and subjectivity of scientists in microscopic image production is common practice. Using software programs to correct, to crop, or to alter images is a commonplace. For instance, color is often added in order to highlight specific elements of an image. Objectivity can be defined as "the suppression of some aspect of the self, the countering of subjectivity" (Ibid., 36). Throughout history different instruments require a different level of suppression and attitude toward suppressing the self.

In modern science such as nanotechnology, scientists can manipulate their sample on a micro scale. Nanotechnology is the manipulation of matter on the scale of atoms and molecules. The microscope becomes the hammer where the scientist sculpts the image into form: "With clicks and keystrokes, these digital images are meant to be used, cut, correlated, rotated, colored" (Ibid., 383, emphasis added). The image can be altered at multiple levels. Daston and Galison separate the practice of manipulation into virtual images and haptic images. Virtual images are a presentation of nature that 
are stored as a data set in image galleries and can be modeled after creation. Haptic images are a presentation of nature that is modified before the image is taken. Tools that afford the creation of both virtual and haptic images are microscopes like the scanning tunneling microscope (STM), or the scanning electron microscope (SEM). These microscopes can change the specimen under the microscope at an atomic and molecular level: "[T] he same device was used at one and the same time to image and to alter" (Ibid., 402). The STM captures atoms by tunneling signals in high vacuums, such as water. For a sample to be analyzed by the SEM, it needs to be plated in specific types of metal, for instance gold. This limits the type of specimens that can be analyzed, but does afford the scientist the ability of manipulation on a nano scale. As illustrated in the previous section, the affordance of the microscope is both influencing in, and influenced by scientific practice. The function and use of the microscope allow for manipulation of the image beforehand and after. Here, we see how the notion of objectivity is problematized, as data are manipulated on multiple levels. How can it still be classified as 'objective' when specimens are manipulated? A partial explanation lies in the materialization of microscopic images in different (scientific) contexts.

\section{Materialization of the image}

The subjectivity of digital scientific images is hidden under the cloak of mechanical objectivity. Sociologists Karin Knorr-Cetina and Klaus Amann dissect the constructed nature of images in scientific research, and argue "images are not just taken, they are designed and made" (1990, 259). Different environments play a role in knowledge creation, namely "the domain of laboratory practice; the context of invisible physical reactions; the future image as it will appear in publication; and the domain of case precedents and reference" (Ibid.). The image can be both an object of knowledge creation, and an object used to illustrate an argument. Voicing a similar argument, media scholars Mirko Tobias Schäfer and Frank Kessler show that the notion of mechanical objectivity is also present in the computational power of the computer $(2013,14)$. Computational processes that create digital images are ambivalent, because these images can change in context and be turned into different arguments. The universality of the computer and its software materializes scientific images in variable contexts. Physical, mechanical, and electronic techniques in the creation and manipulation of images are translated into software programs that can edit images with the click of a mouse. These types of software share the same environment and start to interact, mutate, and create hybrids. Lev Manovich refers to this as media 
hybridization. As he points out, "the unique properties and techniques of different media have become software elements that can be combined together in previously impossible ways" (Manovich 2013, 176). Considering the different techniques working together to create a scientific image, it becomes a hybrid product between the producer, their knowledge and intent, as well as the different materials with which it is made. For example, a scientist can use software programs — such as Photoshop—-to alter images pixel for pixel, in the same way a designer does. ${ }^{1}$ When analyzing microscopic images, it becomes clear that media hybridization also influences identity expressions of the scientist.

Analyzing the oscillation of objectivity and subjectivity in microscopic image production, Galison recognizes the scientist's self diverging into other expressions such as those of an artist (2010, 29). One example of this crossover is the Dutch microscopist Frans Holthuysen, who works as a researcher at Philips and makes images with a SEM-microscope for his research projects at the MiPlaza's Technology Laboratories Group. The images produced by Holthuysen not only have their scientific purpose, they also have aesthetic value. For instance, he won second prize at the MNE micro and nano-graph contest. This contest selects the best micrography images submitted by not only scientists, but also artists. The microscopic images Holthuysen makes have often been published and displayed at different museums, such as the 'design and the elastic mind' exposition, held at the Museum of Modern Art in New York in 2008 (Museum of Modern Art 2008). Holthuysen combines the ethos of a scientist and artist, playing around with his images in different contexts. The relationship between digital practice, microscopic image technology, and the producer's intent creates room for a playful appropriation of images. Photoshop or other programs, invite scientists to play with their data and appropriate images. While the extent of manipulation differs depending on the context, it cannot be denied that the availability to alter and enhance the image changes the epistemic message of the image itself. The boundary between science and culture is blurred as images meant for scientific research travel outside the lab and find their way in to museums. This cultural appropriation also works the other way around, as citizens are increasingly invited to participate in scientific research.

1 Manipulating images for publications is a grey area in scientific research. An ongoing debate in scientific journals and magazines such as PLoS One or Nature, is concerned with the fine line between what is considered as fraud, or the 'beautification' of scientific images (Gilbert 20o9). In response, many of these journals have created guidelines for editing images. 


\section{Rise of citizen science games}

Digital technologies and the internet infrastructure stimulated the involvement of amateurs and non-professionals in scientific research. Mobile and wireless technology has aided in the increase of non-professionals in the collection of data. This is stimulated by openness and collaboration, where interactions between users produce new insights about larger sets of scientific data. Henry Jenkins has dubbed this concept 'participatory culture': a culture with the presence of "artistic expression and civic engagement, strong support for creating and sharing one's creations, and some type of informal mentorship" (Jenkins et al. 2006, 3). Citizen science is the practice of research by amateurs and non-professionals, who use decentralized communication and media to collect scientific data and produce new knowledge. Crowd-sourcing and open research seem to be central ideas to this development.

Play as an epistemological tool can be used to better understand the development of citizen science and its role in the scientific community. Play is both an activity and an attitude. As an activity, play is an expression, "a mode of being in the world" (Sicart 2014, 2). We play board games and digital games, but we also play with technologies such as a smartphone. Indeed, we also play with software and hardware. However, why do we play around with some objects and not with others? I argue that it has to do with the design of the object and conditions of its use. Play happens in contexts that afford that activity, and this is created not only through rules, but also through objects, situations, and spaces. In other words, "[p]lay is contextual" (Sicart 2014, 6). Citizen science, seen from the perspective of play, redefines what it means to do science. The traditional rules of engagement in scientific knowledge production are very closed, as only trained scholars are deemed suitable to collect and interpret data. However, in citizen science projects, which are based on data collection by non-professionals and amateurs, everybody can participate in the creation of knowledge. As illustrated below, there are different forms in which this takes place.

Within the boundaries set by the producers of the project, citizen scientists are able to aid in the production of knowledge. This context lends itself to play, as the player is able to move around within a closed system. More recently, collecting scientific data has been transformed into games. One example of an organization avidly developing games is the Defense Advanced Research Projects Agency (DARPA) Crowd Sourced Formal Verification (CSFV) program, which has established VeriGames, a project to develop several citizen science games where players aid in collecting data by playing 
games. One example is Binary Fission, a puzzle game where players are Fission Initiative Network (FIN) agents and have to separate blue particles from orange particles to create sets for further processing. Binary fission is a biological process of division. For instance, the division of a cell into two cells, which can be analyzed under a microscope. Interestingly, although the representation of this microscopic process is visually presented to the player, it serves as mere decoration. For the game's producers, the valuable knowledge lies in mining the player's actions in the game. Behind this playful layer, algorithms are being tested for their correctness and the value of this application is the formal verification of software.

Binary Fission illustrates two critical issues concerning the role of citizens in citizen science projects. First, player agency and intent may provide different outcomes in the game. For instance, as a player in Binary Fission, I can decide that I want to play with different objectives. Instead of trying to separate the blue and yellow atoms, I can decide that I will try to pack as many atoms together, consequently changing the outcome. This agency of the user to play with the rules, problematizes data collection in the sense that it raises questions about the concept of validity. In the game, the player is not anonymous, since playing involves registration and the player has to sign in to play. As a consequence, the registered player/data collector could hypothetically be excluded from the study if he or she does not follow the rules. Although in some projects the collective wisdom of the crowd might eliminate the deviation of some data collectors, this process is not so easily traceable in other citizen science projects. Similar issues are raised by Glas and Lammes in Chapter 11 of this volume. Are citizen science projects only successful if the result can be quantified, measured, and validated? If so, then the future of this type of informal knowledge production will lead to homogenous projects for the 'hard' sciences. Therefore, we may need to come up with other types of data collection instead.

The second issue in citizen science projects like these is the political question of who benefits from the knowledge produced. In this particular example, the beneficiaries of the game are Verigames and DARPA, since the player is not actually aware of the results of his or her effort. It seems that the status quo of traditional scientific practice is not really disrupted. Instead, the player is used as a data-mining machine to generate small pieces of information. Just as we play around with toys, we play around with media. But toys, just as media, can be appropriated in different ways, and even be destroyed. Play is an appropriation of objects such as Binary Fission, or microscopes. As a result, play can be destructive, political, and serious. This is what scholar Mary Flanagan (2009) calls "critical play," or 
Miguel Sicart (2014) defines as "carnivalesque play." This form of play "takes control of the world and gives it to the players for them to explore, challenge, or subvert. It exists; it is part of the world it turns upside down" (Sicart 2014, 4). As I will illustrate later in this chapter, biohacking is a perfect example of this appropriation.

Citizen science projects and biohacking activities are both activities performed by non-professionals, artists, or citizens, but with a different mode of appropriation. While the intent of citizen science projects is to contribute to research experiments and contributors are expected to 'follow the rules,' biohacking is a bottom-up movement that is based upon subverting existing knowledge structures. When historian Johan Huizinga theorized the role of play in everyday life, he discerned between four different types of "players" (Raessens 2014, 106). These four types of users have different attitudes toward objects or events. First, there is the regular user who does not question the rules of the system and follows them blindly. Second, there is the cheater, who only "pretends to be playing the game" (Huizinga 1955, 11). This is a player who does not play by the rules of the game and cheats in order to advance. This user is aware of the implicit and explicit rules. Third, there is the spoilsport, or the modder in modern terms, who modifies the rules of the game if the system will afford it. Open source products afford this modularity, since users are able to remix and alter the work. Finally, there is the "outlaw, the revolutionary" (Ibid., 12). These users transcend the system by inserting new ideas and functions in the game, consequently altering the entire system. For a citizen science project to succeed, the game needs regular players that behave and play the game as it was intended. While games such as Binary Fission rely on players to follow the rules and try to discourage cheating, in biohacking, the user is invited to be an outlaw by hacking and modifying the system.

In summary, I have shown from a broader perspective the dual function of scientific images as a source of knowledge and of evidence. The examination of microscopic image production revealed that digital images can be shaped in any form or according to any illustrative argument. Even though manipulation is becoming more common in pre- and postproduction of the image, dissecting this image reveals the symbolic and functional role of objectivity. Play as both an activity and an attitude is instrumental in citizen science projects. However, different levels of playability illustrate that concepts like objectivity need to be redefined. Furthermore, the extent to which these projects emancipate science is questionable. In a way, biohacking is a response to this. In the next section, I will unpack where and how this 
play takes place to illustrate how hacking lab equipment is a critical and playful appropriation of science.

\section{Playfulness of hacking}

In this section, I trace the process of decoding and encoding the microscope from the lab to the open hacker space and the attempt of biohacking to emancipate science from its institutional form. First, I trace the relationship between biohacking ideology and scientific knowledge production, which is illustrated by the act of hacking lab equipment. Then, I explore how hacking as a playful practice can be seen as a playful form of knowledge production. In the subsequent sub-sections, I trace hacking as a playful practice by closely analyzing Hackteria's DIY microscope. Lastly, I illustrate how the player and the microscope's design inform the type of knowledge produced.

\section{Political message of biohacking}

What kind of knowledge is produced in biohacking, and how does this relate to science? We have seen the function, manipulation, and regulation of knowledge production in science, and how citizen science complicates notions of validity and objectivity. In order to place practices of the DIY microscope in this context, both the images produced and the microscope will be analyzed. The environment and personal background of the producer influence the use of the microscope as an instrument and therefore a closer analysis of biohacker ideology is needed.

Biohacking brings biotechnology and lab instruments to a context that affords play. Biohacking is an expression that describes emerging movements of amateurs conducting life sciences outside traditional settings such as the lab or universities (Delfanti 2012, 163). Very often low-cost equipment is made in order to experiment outside the lab. One creation is the DIY microscope, developed in 2009 by micro- and nanoscholar Marc Dusseiller. The DIY microscope is made with open source ideology in mind, which means the microscope's design for everyone. In this context, it means “'free speech' not free beer" (Weber 2004, 5). Open source software (OSS) is computer software which is design to be released non-commercially. According to the Open Source Initiative (OSI), the main characteristics of OSS are its modifiable nature, public availability, and open distribution (Open Source Initiative n.d.). Open source hardware is based on the same principles. The ideology of open source is based on open distribution and 
modification and availability for everyone. Biohacking can be seen as a hybrid of open source ideology and hacker practices in the scientific realm of biology, life science, and biotechnology. Moving biotechnology from the context of a formal lab environment to a hacker space introduces these tools, technologies, and processes to non-professionals and amateurs. This results in the introduction of different approaches and appropriations of biotechnology and equipment. Hacking can be seen as this sort of appropriation, which is defined as an activity that appropriates material objects such as computers, or immaterial objects such as software in an attempt to redefine the existing system and subvert its affordances. Hacking as a form of play is "a contextual appropriation of a situation with the purpose of creating new values, expressions, or knowledge" (Sicart 2014, 67). Although play is formally bound to specific rules in a specific space, hacking as a playful practice renegotiates the existing status quo, or game, if you will. The intent is to purposefully create new ideas, knowledge, generate different values and to go against the grain. A biohacker space is the ideal ground for re-appropriating existing technologies and generating different scientific values. One such an example is Hackteria, an online platform, which advocates the open sharing of knowledge, open source technology and art in biology, life science and biotechnology (2013a; 2013b). Founded in 2009 by artist Andy Gracie, nano-scientist Marc Dusseiller, and artist Yashas Shetty, Hackteria publishes open source designs online and organizes workshops where they collaborate together with scientists, artists, educators, engineers, and hackers to create knowledge and share ideas. One central activity is hacking lab equipment together in order to share this technology with a wider public. The foundation is based on temporal spaces, and the emphasis is on mobility. This less formal context explicitly tries to be break open scientific knowledge production, which is reminiscent of the level of playability mentioned in the previous section.

The modder and hacker tries to divert the system by making up his/her own rules. The ethos of biohackers to deinstitutionalize science manifests itself in the practice of hacking lab equipment, and sharing those designs with the use of open web tools for collaboration such as wikis. Sociologist Allesandro Delfanti observes the development of biohacking as an ethos of activism, entrepreneurship, and artistic expression. According to this perspective, the practice "can be interpreted as an example of a direct transposition of free software and hacking practices into the realm of cells, genes, and labs" (Delfanti 2012, 163). What is clear is that biohackers are changing the rules of the system by bringing commercial lab equipment 
outside the traditional lab environment, and creating open source models based on these technological principles.

According to Delfanti, hacking lab equipment can be seen as an "active approach in the shaping of the institutional environment in which biological research takes place and in the questioning of the proprietary structure of scientific information" (2012, 164). Arguing for the relevance of biohacker spaces like Hackteria, Kera and Dusseiller point out these spaces are "becoming important sites of translation between scientific knowledge and technological innovation produced in the traditional and official labs and the everyday interests, practices and problems of ordinary people around the world" $(2012,3)$. As part of their argument, the authors illustrate their desire for hacker practices to liberate scientific knowledge. However, the question can be raised whether the practice of biohacking actually contributes to scientific research not just in the traditional sense. To evaluate if this is actually the case, we will need to take a closer look at the practice of making the DIY microscope. As Wise points out, when "the subject of making visible in science leaves the domain of mere illustration or mere technology and becomes a matter of making knowledge, then the making acquires much higher status" (2006, 79). By analyzing materiality, I aim to provide more clarity about the epistemic message of biohacker practices.

\section{Materiality of playing}

Figure 10.1 is an example of a DIY microscope that citizen scientists can create and use to analyze specimens. Since the instrument is also produced by the user, biohacking practices like the DIY microscope make hybridity of image and producer even more complex. There are multiple layers of materiality that affect image production. Just as Ann-Sophie Lehmann argues, the process of making an image has multiple layers of materiality, "from the making that leads to its encoding, to the material reality of the code itself, the CG [computer graphic] object being in-material, the simulation of diverse material qualities and therefore being all-materials, and finally, its re-translation into the analogue" $(2012,183)$. The process of interacting with different layers of material creates a deeper understanding of the thing itself.

How does this biohacker context materialize itself in an environment for playful knowledge production? The availability of open source software and hardware designs invites open-ended play. Playing, or tinkering affords knowledge of the object at hand. Tinkering, which is closely related to playing, is an iterative style of learning, where users learn about a technology through open-ended interaction (Resnick and Rosenbaum 2013). The relationship 


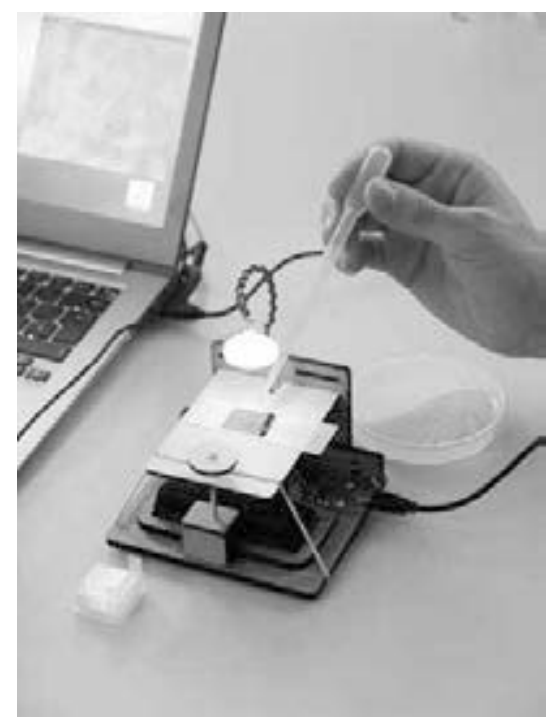

10.1: The DIY microscopy stage kit (Hackteria.org).

with tinkering highlights the material aspects of playing. This approach is often seen in do-it-yourself(DIY) and maker cultures. The rapid development of the consumer $3 \mathrm{D}$ printer is one example of the playful engagement with materials, as users literally have to put their own device together. As I noted elsewhere, playing around with technology enables a deeper understanding and stimulates creativity (de Smale 2014). In the case of the ${ }_{3} \mathrm{D}$ printer, this has led to innovations in software and hardware that would not have been developed elsewhere. Due to the subjective nature of experience it is not possible to create experience, however, it is possible to design for a specific experience (Arrasvuori et al. 2011, 3). This suggests that there are specific design principles that afford the context of play. Play scholars Mitchel Resnick and Eric Rosenbaum $(2013,174)$ identify design principles that afford playful knowledge production: fluid experimentation, immediate feedback, and open exploration. The extent to which these design principles are found in the material layers of the DIY microscope will be explored below.

\section{Fluid experimentation}

The first layer of materiality is the process of making and encoding the DIY microscope. The inspiration for the DIY microscope with laser cut $\mathrm{Z}$-stage is a regular optical microscope. Figure 10.2 shows the design for the Z-stage - drawn by Marc Dusseiller. In 2009, Dusseiller first wrote about hacking a digital microscope he called the DIY microscope. The DIY 


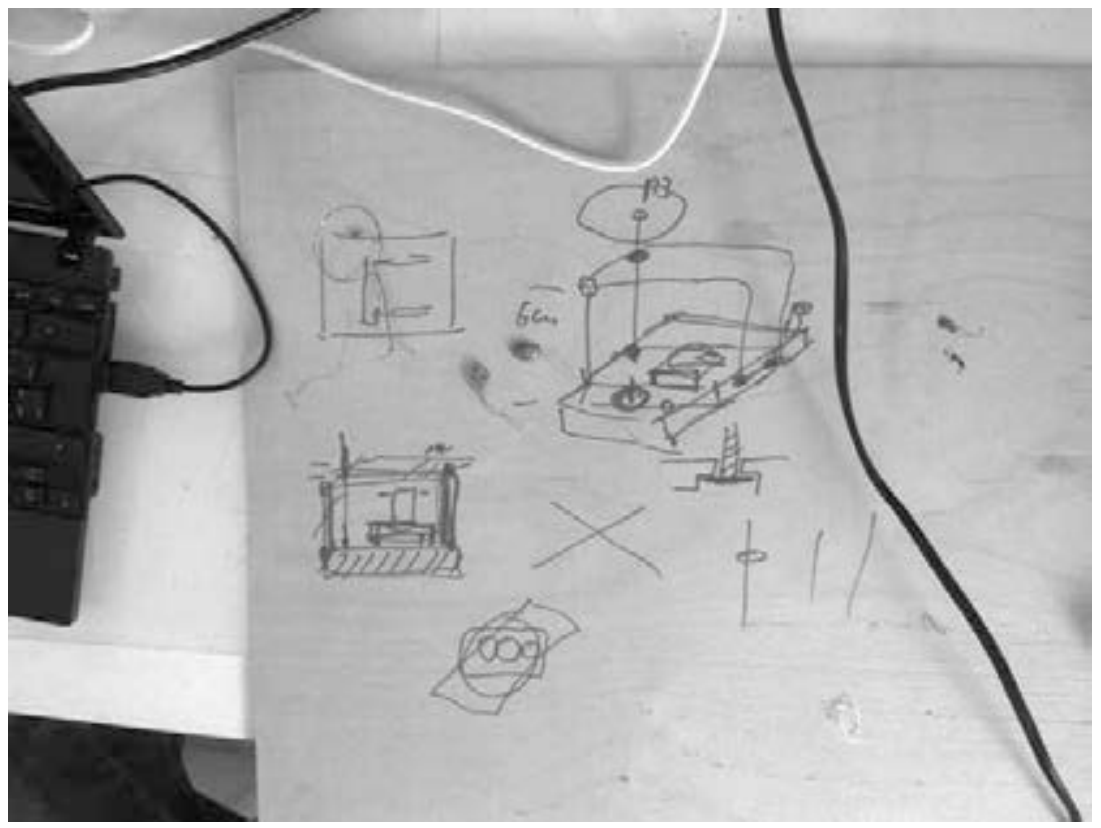

10.2: Designing the DIY microscope (Hackteria.org).

microscope has many different forms and designs, but the basic principle is hacking a digital camera, for instance a webcam. The camera is attached to a microscopic lens, and mounted on a Z-stage that can be made of plywood, plastic, glass, or any other hard material available. Practices like hacking lab equipment are as much an epistemic statement, as a tool for the production of images.

The open source nature of the DIY microscope allows for fluid experimentation, stimulating a context of play: "Tinkerers start by exploring and experimenting, then revising and refining their goals, plans, and creations" (Resnick and Rosenbaum 2013, 176). Prototyping is a technique for fluid experimentation that allows for fast results and a quick iteration. Figure 10.2 shows how the microscope as a scientific tool is being broken down into parts. The black box of the regular optical microscope is opened up, and translated into a new design. While the affordance of the traditional microscope is most often hidden because of its design, all the parts are visible with the open source design. This serves as an important instrumental function, since it allows for open exploration of the technologies. It is up to the user to assemble the microscope. The process of putting it together is very modular which allows for an iterative style of learning. This design is easily produced in open hacker spaces like Fablab with the help of a 
laser cutter. The original design of the microscope is changed to fit the epistemic virtue of biohackers, namely open source design, availability of biotechnology for the public, and the desire to share knowledge. This is evident in the design choices made by Dusseiller. Materials that are easily ready at hand can be used for this kit. Plexiglas, plywood, glass, or any other material that is hard enough can be used. After the analog drawing, the first prototype is made. The closed objective structure of the microscope is hacked and appropriated into a modular microscope that can be built outside the factory. In this process, the system, technology, and material of the microscope have been altered, affording a high level of playability.

\section{Immediate feedback}

The materiality of code is easily forgotten, but it plays a central role in the playful production of knowledge. After the prototype, the design was drawn in Adobe Illustrator (see Figure 10.3) as a Computer-Aided-Design (CAD). CAD drawings can be seen as a technical blueprint. The user chooses to design in Illustrator because it creates designs that are vector-based. Vectors can be blown up and cropped without losing shape or form. This means the microscope can be as big or as small as desired. The original CAT file is downloadable via wiki. This example illustrates the willingness of biohackers like Dusseiller to share knowledge and designs of the DIY microscope. Even though Illustrator is not open source, the open source ethics of open access for everyone, open distribution, and modularity are present. However, the modularity of shape and size might potentially be a problem with the production of scientific images, since the quality of the photos and the ability of the microscope to zoom may differ which would result in different types of images.

When translating the microscope into open source hardware and software processes, traditional lab space is transgressed. According to Kitchin and Dodge (2011, 61-63), software plays a significant role in the conceptualization of space. Coding the microscope into a machine-readable open source design means it can be distributed freely. Instead of a closed environment that is only accessible for scientists and researchers, hypothetically everyone with an internet connection has access to the design of a microscope. All the information about how to design a DIY microscope was placed on a wiki page. Wiki is a tool for collaboration, and users can also become authors by adding knowledge. The software environment is based on open collaboration, where the process of building a microscope also becomes a means of participation, through the openness and modularity of the software. The malleability of software and the ability to contribute allows for quick results 


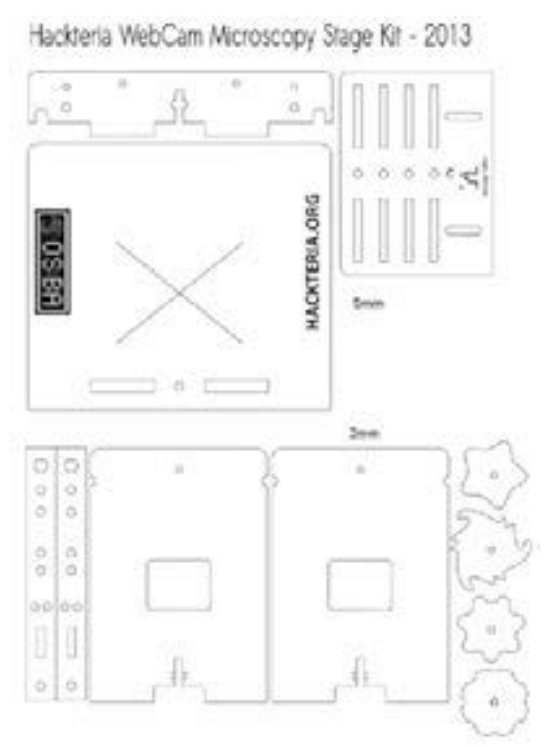

10.3: Encoding the microscope (Hackteria.org).

and feedback. Users are functioning in a context that allows immediate feedback and an environment that stimulates appropriation of existing technologies. By designing the digital environment to encourage tinkering with the design, a playful context is stimulated.

\section{Open exploration}

The ability for users to change the design, size, and materials of their microscope creates a context that allows for open exploration and user agency. As visible in Figure 10.4, its meaning has become modular. The design is flexible and open for the creation and re-creation of different practices. The last material translation is the re-translation from the design into an analog material, the DIY microscope. The materiality of the DIY microscope shows how the scientific image is broken down, and changed with every layer. The re-materialization of the microscope can come in different shapes, sizes and forms. This primarily depends on the choices the user makes in the material design, the type of webcam, and the type of (open source) software that is used. This means all the microscopes will be different, there is not one DIY microscope, but there is the idea of a DIY microscope that is expressed through the user. Offering this type of flexibility enables user agency and stimulates creativity. This creates a setting, a stage that invites players to interact, explore, play, and change the rules. 


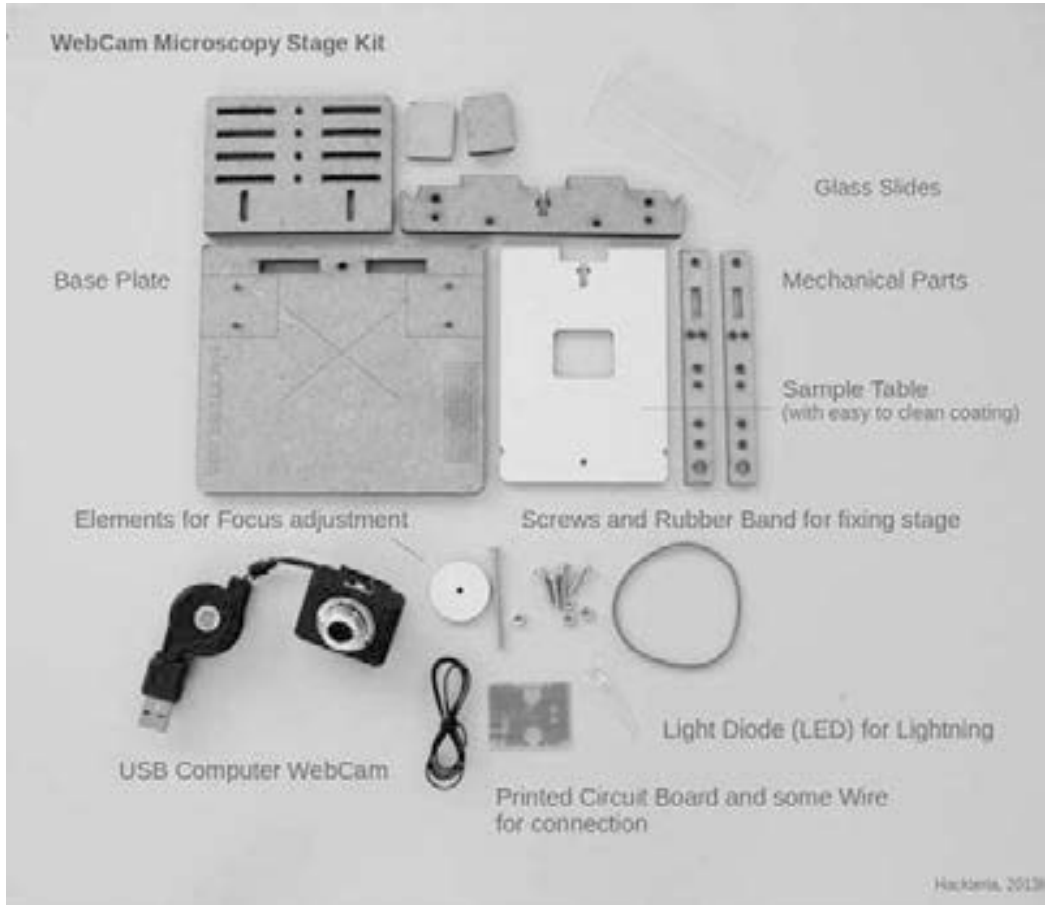

10.4: Materials needed for the DIY Microscope (Hackteria.org).

The analog version of the DIY microscope could not have existed without its digital form and the ability to create the microscope oneself changes the relationship between the producer, image, and microscope. The DIY microscope can be seen as an epistemic image, because it incorporates knowledge about how a microscope works.

This helps to "understand that the medium is not a black box, but an active instance translating, and thus interpreting and shaping, data input into the image we see" (Schäfer and Kessler 2013, 14). The process of building a microscope is equally - if not more -important than creating microscopic images. The value of the knowledge produced is not as much about what is seen under the microscope, but what it is made of. A microscope in science is used to analyze specimens and collect data. The microscope is a tool to achieve this goal. However, in the example of the DIY microscope it seems that the value lies more in the process itself and knowledge produced for the user. 


\section{Knowledge production}

When analyzing the type of images that were produced and published on the Hackeria platform, it is evident the process of building a DIY microscope and of producing microscopic images cannot be separated. When looking at the images produced, there are two sets of images. On the one side, images that share knowledge about the process of building a device like the DIY microscope. On the other side, there are microscopic images that were made with the DIY microscope. But these images represent the end product, and are shown as part of the process of building. Figure 10.5 is an example of the appropriation of microscopic images with the use of a DIY microscope. Here, students at the Bauhaus-Universität Weimar hacked a webcam, made the DIY microscope, and created microscopic images to use in an artistic project. Analyzing its use, these images were used in creative contexts like an art project, or video projection. While the image has lost a direct scientific purpose, it has gained cultural and educational value. The environment of shaping an image is broadened, and the producer has both shaped and is shaping the production process. Comparing this with the citizen science game Binary Fission, there is a different output in knowledge production. In the game, the output is the data produced by the player. The player actively participates in knowledge production, but is left to wonder what the purpose of their participation is. With biohacking and the DIY-microscope, the value is much more process-oriented and dependent on the user's intent. The output of knowledge is not about the end product, such as the collection of data. Rather, it is about knowledge of technological processes and systems. Its value lies in understanding the technology and how it is made, and the pleasure is not in playing a game, but understanding the rules of the system and choosing to comply or ignore them. This changes the context of knowledge production. The DIY microscope is no longer a tool for analyzing data, but a process. Although this means that this knowledge is valuable for the player, the output is not necessarily valuable for scientific research. In this sense, hacking the microscope is a fruitful experiment of learning by tinkering, but it leaves the desire of Hackteria to liberate science-as of yet-unfulfilled.

In summary, by analyzing the process of making a DIY microscope, I have exposed the material layers that form the context of knowledge production from a tool for data analysis to a process of the playful production of knowledge. The material layers of the microscope interact to create an environment favorable for play. Fluid experimentation through prototyping, immediate feedback in playing with digital designs, and open exploration 


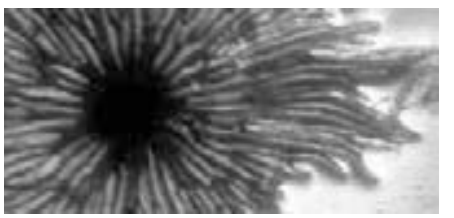

10.5: Appropriation of microscopic images in education (Neupert 2013).

in the form and function of physically making the DIY microscope set the stage for playful learning. As we have seen, the central goal for Hackteria is the practice, creation, and distribution of knowledge in biology, life sciences, and biotechnology. Although, with the case of the DIY microscope, the process of building it is more interesting than the images it creates. Play as epistemology illustrates how the practice of hacking is a context that affords the playful appropriation of science.

\section{Conclusion: Image production from the lab to playful hacker spaces}

The DIY microscope is a critical product of playful experiments to democratize science. In this form, it is not so much about the knowledge produced with the device, as about the valuable knowledge produced in hacking the microscope and creating open source variants. Citizen science projects like Binary Fission use those who play science games as data-collecting machines, where the design of the game allows little agency for the player. This formal environment of data collection does not emancipate science, but instead re-enforces a hierarchical, institutional form of science. An extension of that development - and in some parts a reaction to-is biohacking. The political message behind hacking lab equipment is the attempt to deinstitutionalize science.

Biohacking practices like the DIY microscope are still in an experimental stage, and the lens of play can help to explain how transporting the microscope from the lab to open hacker spaces alters its context. There is a specific form of play in biohacking since it creates a context for tinkering. Play is materialized in the design principles of fluid experimentation, immediate feedback, and open exploration. First, fluid experimentation is seen in the rapid iteration of building prototypes, of hacking the microscope and translating it into an open source microscope. From a user perspective, building a microscope creates the opportunity to learn how it works, and what the technological limits are. Second, immediate feedback 
is afforded through the adaptability of software. Third, open exploration is seen in the agency of the user to build the DIY microscope with any material and in any size he/she desires. Subsequently, there is a strong educational value in learning to understand how the microscope works. Yet the microscopic images that are produced with the DIY microscope are often used in an artistic or cultural context, where the artistic value is more important than the images possible scientific value. These images are part of the material process of creating a microscope, not of creating objective images.

On a broader level, digitizing the microscope "modulates the conditions under which sociospatial processes operate" (Kitchin and Dodge 2011, 64). This is visible in the translation of the microscope from the lab to the open hacker space. When image production moves from a closed centralized scientific environment to an open decentralized hacker environment, production becomes more complex. More layers of materiality affect shaping of the image, and the producer is intimately connected with the microscope. As a result, the process of production creates valuable knowledge for the user about technology and the system of the DIY microscope. It is too early to tell if the open source lab equipment is suitable for scientific data collection, but for me this is not the point of hacking lab equipment. Perhaps liberating science is found in educating a wider public about scientific instruments and how they can be made and used. While the motivation of translating the microscope may be political, the means through which this is achieved is play.

\section{References}

Arrasvuori, J, M. Boberg, J. Holopainen, H. Korhonen, A. Lucero, and M. Montola, 2011. Applying the PLEX framework in designing for playfulness. In Proceedings of the 2011 conference on designing pleasurable products and interfaces, Milan, June 22-25, 2011. New York: ACM.

Daston, L., and P. Galison. 2007. Objectivity. Cambridge, MA: The MIT Press.

Delfanti, A. 2012. Tweaking genes in your garage: Biohacking between activism and entrepreneurship. In Activist media and biopolitics critical media interventions in the age of biopower, eds. W. Sützl and T. Hug, 163-178. Innsbruck: Innsbruck University Press.

De Smale, S. 2014. Building material: Exploring playfulness of $3 \mathrm{~d}$ printers. Transactions of the Digital Games Research Association 1 (3): 1-31. http:// todigra.org/index.php/todigra/article/view/21/74. 
Flanagan, M. 2009. Critical play: Radical game design. Cambridge, MA: The MIT Press.

Galison, P. 2010. The objective image. Inaugural Address. Faculty of Humanities: Utrecht University.

G-netwerk. 2013. Day 2 Denisa Kera the future of art \& science collaborations. Amsterdam: G-netwerk. Video. http://www.youtube.com/watch?v= qkr7tAGwc\&feature $=$ c4-overview\&list=UUq-ZlKq8aZL_7Y-orBGtoxw.

Gilbert, N. Science journals crack down on image manipulation. Nature. http://www.nature.com/news/2009/og1009/full/news.2009.991.html.

Hackteria. 2013a. DIY Microscopy. Hackteria. http://wlu18www30.webland. ch/wiki/index.php?title=DIY_microscopy.

—. 2013b. Laser cut microscopy stages. Hackteria. http://wlu18www3o. webland.ch/wiki/index.php?title=Laser-cut_microscopy_stages.

Huizinga, J. 1955. Homo ludens: A study of the play-element in culture. Boston, MA: Beacon Press.

Jenkins, H., K. Clinton, R. Purushotma, A. J. Robinson, and M. Weigel. 2006. Confronting the challenges of participatory culture: Media education for the $27^{\text {st }}$ century. Chicago, IL: MacArthur Foundation. http://www.macfound. org/media/article_pdfs/JENKINS_WHITE_PAPER.PDF.

Kera, D., and M. R. Dusseiller. 2012. Position statement: Hackteria. org - Nomadic science and democratized labs. Sead: White papers. http://www.academia.edu/2420045/Position_statement_Hackteria. org_-_nomadic_science_and_democratized_labs.

Kitchin, R., and M. Dodge. 2011. Code/space: Software and everyday life. Cambridge, MA: The MIT Press.

Knorr-Cetina, K., and K. Amann. 1990. Image dissection in natural scientific inquiry. In Science, Technology, \& Human Values 15 (3): 259-283.

Lehmann, A. 2012. Taking the lid off the Utah-teapot: The materials of computer graphics. Zeitschrift für Medien und Kulturforschung, 1:157-172.

Manovich, L. 2013. Software takes command. New York: Bloomsbury.

Museum of Modern Art. 2008. Design and the elastic mind. New York: $\mathrm{Mu}$ seum of Modern Art. http://www.moma.org/interactives/exhibitions/2008/ elasticmind.

Neupert, M. 2013. A rewarding challenge: DIY-microscopy. Hackteria. http:// hackteria.org/?p=2674.

Open Source Initiative. n.d. Open source definition. Open Source Initiative. http://opensource.org/osd.

Raessens, J. 2014. The ludification of culture. In Rethinking gamification, eds. M. Fuchs, S. Fizek, P. Ruffino, and N. Schrape, 91-114. Lüneburg: meson press. 
Resnick, M., and E. Rosenbaum. 2013. Designing for tinkerability. In Design, make, play: Growing the next generation of stem innovators, eds. M. Honey and D. E. Kanter, 163-181. New York: Routledge.

Schäfer, M. T., and F. Kessler. 2013. Trust in technical images. Mtschaefer. net http://mtschaefer.net/entry/trust-technical-images.

Sicart, M. 2014. Play matters. Cambridge, MA: The MIT Press.

Verigames. 2015. Binary Fission. [browser]. Verigames. Game.

Weber, S. 2004. The success of open source. Cambridge, MA: Harvard University Press.

Wise, M. N. 20o6. Making visible. Isis, 97 (1): 75-82.

\section{About the author}

Stephanie de Smale is a new media researcher at the department of Media and Culture Studies at Utrecht University, and is affiliated with the Centre for the Study of Digital Games and Play and the Centre for Conflict Studies. Her background is in communication and new media studies, specializing in games and play, design, politics, and violent conflict. Currently pursuing a doctoral degree, her NWO-funded research is a computer science/humanities collaboration that combines approaches from software studies, game studies, and conflict studies to analyze how wartime suffering is imagined and remembered in translocal digital culture communities and what its potential is for peacebuilding and postwar reconciliation in divided societies. 